\title{
CAPÍTULO 09: BEBIDA FERMENTADA A BASE DE EXTRATO HIDROSSOLÚVEL DE AVEIA EM INFUSÃO DE MAÇÃ COM CANELA
}

\section{CHAPTER 09: FERMENTED DRINK BASED ON WATER-SOLUBLE OAT EXTRACT IN INFUSION OF APPLE WITH CINNAMON}

Shirley Santos Monteiro ${ }^{1}$; Shênia Santos Monteiro ${ }^{2}$; Andréa Trigueiro Lima ${ }^{3}$ Thaisa Abrantes Souza Gusmão $^{4}$

\begin{abstract}
Resumo
O mercado de bebidas lácteas seja popular e amplamente aceito pelos consumidores, a demanda por bebidas não lácteas tem crescido exponencialmente em função das desvantagens das bebidas lácteas. Diante disso, o objetivo desse trabalho foi avaliar os efeitos das concentrações de goma xantana e sacarose na textura e parâmetros sensoriais da bebida fermentada a base do extrato hidrossolúvel de aveia em infusão de maçã com canela. Foi avaliado a concentração de goma xantana $(0,1,0,3$ e $0,5 \%)$ e sacarose $(5,0$, 7,0 e 9,0 \%) no pH e acidez das bebidas fermentadas, usando as cepas Streptococcus thermophilus e Lactobacillus bulgaricus. As avaliações os efeitos das formulações foram realizados por planejamento fatorial completo $2^{2}$, três repetições no ponto central nos parâmetros de textura. Os diferentes perfis de textura das bebidas foram analisados através da sensorial. Observou-se o aumento da consistência e do índice de viscosidade das bebidas com o aumento da concentração de goma xantana. A análise sensorial indica que as concentrações de $0,3 \%$ de goma xantama e 7,0\% de sacarose foram as indicadas para elaboração de uma bebida fermentada a base do extrato hidrossolúvel de aveia em infusão de maçã com canela.
\end{abstract}

Palavras-Chaves: Goma xantana, Lactobacillus bulgaricus, Sacarose, Streptococcus thermophilus.

\begin{abstract}
The dairy beverage market is popular and widely accepted by consumers, the demand for non-dairy drinks has grown exponentially due to the disadvantages of dairy drinks. Therefore, the objective of this work was to evaluate the effects of xanthan gum and sucrose configurations on the texture and sensory parameters of the fermented drink based on water-soluble extract of oats infused with apple and cinnamon. The concentration of xanthan gum $(0.1,0.3$ and $0.5 \%)$ and sucrose $(5.0,7.0$ and $9.0 \%)$ without $\mathrm{pH}$ and acidity of fermented drinks was evaluated, using Streptococcus thermophilus as strains and Lactobacillus bulgaricus. The effects of the effects of the formulations were carried out by the complete $2^{2}$ factorial design, three repetitions at the central point in the texture parameters. The different texture profiles of the drinks were visible from the sensory. Observe the increase in the consistency and the viscosity index of the drinks with the increase in the concentration of xanthan gum. A sensory analysis indicates that the restrictions of $0.3 \%$ of xantama gum and $7.0 \%$ of sucrose were indicated for the preparation of a fermented drink based on water-soluble extract of oats in apple and cinnamon infusion.
\end{abstract}

\footnotetext{
${ }^{1}$ Doutoranda em Engenharia Agrícola, UFCG, shirley_pinto_monteiro@ hotmail.com

2 Mestranda em Engenharia Agrícola, UFCG, shenia-monteiro@ hotmail.com

${ }^{3}$ Graduada em Engenharia de Alimentos, UFCG, andrea trigueiro@ hotmail.com

${ }^{4}$ Doutora em Engenharia de Processos, UFCG, ta_brantes@ hotmail.com
} 
Keywords: Xanthan gum, Lactobacillus bulgaricus, Sucrose, Streptococcus thermophilus.

\section{Introdução}

Um novo campo de pesquisa vem abrindo o espaço para estudos fundamentais que tratam de características funcionais em alimentos capazes de promover benefícios a saúde. Embora os iogurtes e os leites fermentados sejam os mais populares, a demanda dos consumidores por bebidas não lácteas, com alta aceitação e funcionalidade, está aumentando. As desvantagens dos leites fermentados são principalmente a tendência contínua do vegetarianismo, a crescente prevalência de intolerância à lactose e o nível de colesterol dos produtos lácteos (CODA et al., 2012; GOBBETTI et al., 2010; PRADO et al., 2008).

Nos últimos anos tem sido cada vez mais frequente a ocorrência de pessoas com algum tipo de restrição alimentar. Fato que faz com que a indústria de alimentos esteja cada vez mais em busca de desenvolvimento, buscando se adaptar a uma nova realidade exigida pelo mercado (BELTRAN, 2017).

A preparação de bebidas vegetais fermentadas tem um grande potencial na elaboração de um novo produto funcional (SHORI, 2016). Frutas, hortaliças e cereais podem ser utilizadas como substratos para substituição da fonte láctea, porém estudos devem ser feitos para determinação de espécies apropriadas, viabilidade celular e a sobrevivência dos micro-organismos ao longo da estocagem, bem como a aceitabilidade sensorial do consumidor (SHORI, 2016). Estes produtos vegetais probióticos representam um grande potencial de crescimento para a indústria de alimentos podendo ser assim, explorados por meio do melhoramento dos novos ingredientes, processos e produtos (DEZIDERIO, 2019).

Neste sentido, para Yépez et al. (2019), as bebidas funcionais à base de cereais representam possibilidades sustentáveis em termos sociais. Obviamente, que para explorar o potencial de extratos vegetais na produção de bebidas fermentadas, é necessário investigar sua composição físico-química e suas características sensoriais e microbiológicas (KIZZIE-HAYFORD et al., 2016).

As bebidas à base de cereais têm um enorme potencial para atender a essa expectativa e atuar como veículos em potencial para compostos funcionais como antioxidantes, fibras alimentares, minerais, prebióticos e vitaminas (KREISZ et al., 2008). As bebidas fermentadas com aveia são chamadas de funcionais por causa do efeito 
simbiótico de culturas iniciadoras de probióticos e a fibra prebiótica b - glucana (ANGELOV et al., 2018). O mercado de alimentos e bebidas funcionais evoluiu consideravelmente, à medida que as pessoas se tornam mais e mais preocupados com sua qualidade de saúde e estilo de vida (SALMERÓN et al., 2015; SHAH et al., 2016). O grão de aveia tem um alto potencial funcional devido à sua composição. Aveia é conhecida ser uma excelente fonte de fibra alimentar, antioxidantes e uma fração proteica bem equilibrada (ANGELOV et al., 2018; SHAH et al., 2016).

A aveia destaca-se entre os cereais por fornecer aporte energético e nutricional equilibrado, conter em sua composição química aminoácidos, ácidos graxos, vitaminas e sais minerais indispensáveis ao organismo humano e, principalmente, pela composição de fibras alimentares (WEBER et al., 2002).

Agregando ainda mais propriedades funcionais a uma bebida fermentada a base de aveia, a incorporação de infusões a exemplo de canela, uma especiaria amplamente usada que é frequentemente adicionado a diversos produtos com leite, permite a elaboração de um produto com um diferencial inovador que atenda uma vastas variedades de público, com restrições alimentares aos derivados de leite. Uma vez, que a canela contém compostos funcionais usados para superar problemas digestivos, diabetes, inflamação e atividade microbiana (MUHAMMAD; DEWETTINCK, 2017). Assim como, a maçã que contém em sua composição compostos bioativos com propriedades funcionais que podem provocar efeitos benéficos a saúde do consumidor.

Uma variedade de tecnologias (por exemplo, cozimento, brotação e moagem) é rotineiramente usada para processar cereais, mas a fermentação continua sendo uma das melhores opções para melhorar as propriedades nutricionais e sensoriais e o prazo de validade (MATTILA-SANDHOLM, 1998). Diante disso, o objetivo desse trabalho foi avaliar os efeitos da concentração de goma xantana e sacarose na textura e parâmetros sensoriais da bebida fermentada a base do extrato hidrossolúvel de aveia em infusão de maçã com canela.

\section{Material e Métodos}

O experimento foi conduzido no Laboratório de Engenharia de Alimentos da Unidade Acadêmica de Engenharia de Alimentos do Centro de Tecnologia e Recursos Naturais (CTRN), campus Campina Grande-PB, pertencente à Universidade Federal de Campina Grande (UFCG). A matéria-prima utilizada foi adquirida no comércio da cidade de Campina Grande-PB. 
A infusão foi preparada utilizando saches de maçã com canela na concentração de $1 \%$ da mistura de maçã e canela, permanecendo em infusão durante 10 minutos na temperatura de $80{ }^{\circ} \mathrm{C}$, em seguida foi arrefecido a temperatura de $42{ }^{\circ} \mathrm{C}$.

Para obtenção do extrato hidrossolúvel de aveia, os flocos de aveia foram hidratos durante 20 minutos e posteriormente triturados com a infusão de maçã com canela na proporção 1:6 flocos/infusão, em liquidificador convencional e filtrado.

Para o processo fermentativo foi utilizado cepas desidratadas de Streptococcus thermophilus e Lactobacillus bulgaricus. Foram inoculados $100 \mathrm{mg} . \mathrm{L}^{-1}$ de bactérias láticas em base seca ativa em relação ao volume total do extrato. A fermentação procedeuse na temperatura de $42{ }^{\circ} \mathrm{C}$ até $\mathrm{pH} 4,5$.

A adição da goma xantana nas concentrações de $0,1,0,3$ e $0,5 \%$ e sacarose de 5 , 7 e 9\%, foi realizada de acordo com as concentrações determinadas pelo planejamento fatorial completo $2^{2}$, com três pontos centrais (Tabela 1). Após o termino da fermentação, todas as amostras foram acondicionadas em potes hermeticamente fechados e mantido a temperatura de refrigeração, de $8 \pm 2{ }^{\circ} \mathrm{C}$.

Tabela 1. Matriz do planejamento fatorial completo $2^{2}$.

\begin{tabular}{ccc}
\hline Experimentos & Goma xantana $(\boldsymbol{\%})$ & Sacarose $(\boldsymbol{\%})$ \\
\hline $\mathbf{1}$ & 0,1 & 5,0 \\
$\mathbf{2}$ & 0,5 & 5,0 \\
$\mathbf{3}$ & 0,1 & 9,0 \\
$\mathbf{4}$ & 0,5 & 9,0 \\
$\mathbf{5}$ & 0,3 & 7,0 \\
$\mathbf{6}$ & 0,3 & 7,0 \\
$\mathbf{7}$ & 0,3 & 7,0 \\
\hline
\end{tabular}

Fonte: Própria (2020).

As bebidas foram submetidas as análises de $\mathrm{pH}$ e acidez total titulável. As medidas do $\mathrm{pH}$ foram determinadas utilizando potenciômetro modelo 0400 (Quimis, São Paulo, Brasil), previamente calibrado, a leitura foi feita diretamente no produto, em triplicata. Para acidez, foram homogeneizados 5 gramas de cada amostra com $50 \mathrm{~mL}$ de água destilada, em seguida, a suspensão foi titulada com solução de $\mathrm{NaOH} 0,1 \mathrm{~N}$ até pH 8,5.

O perfil de textura foi determinado através do texturômetro universal modelo TAXT plus - Textura Analyzer do fabricante Stable Micro Systems equipado com o software 
ExponentStable Micro Systems, com utilização do probe A/BE e disco de $35 \mathrm{~mm}$. As analises foram realizadas em triplicata, com altura da amostra de $3,5 \mathrm{~cm}$.

O teste sensorial realizado contou com participação de 50 julgadores não treinados, constituído por discentes, docentes e funcionários da UFCG. Presença de alergias ou intolerâncias alimentares, resfriados e outras alterações de saúde com comprometimento de paladar foram adotados como critérios de exclusão para os participantes. Os julgadores estavam cientes dos objetivos da pesquisa, segundo o termo de consentimento livre e esclarecido (TCLE).

As bebidas foram submetidas a um teste de aceitação, utilizando uma escala hedônica verbal de 9 pontos, com escores variando de 9 (gostei extremamente) até 1 (desgostei extremamente). Os parâmetros avaliados pela escala hedônica foram aparência, aroma, sabor, doçura e textura. Foi avaliado também a intenção de compra, onde os julgadores assinalaram na escala estruturada verbal de cinco pontos (5 Certamente compraria a 1 - Certamente não compraria). As amostras foram servidas à temperatura de aproximadamente $8{ }^{\circ} \mathrm{C}$ em porções de aproximadamente $25 \mathrm{~g}$ apresentadas em copos codificados com números de três dígitos, de forma balanceada e em blocos completos. Um copo com água filtrada à temperatura ambiente foi fornecido para enxague da boca entre as avaliações, o teste foi aplicado em cabines individuais sob luz branca.

Os resultados do planejamento fatorial completo $2^{2}$ com três repetições no ponto central foram comparados por meio de análise de variância seguida da metodologia da superfície de resposta, e as diferenças foram consideradas significativas para valores de $\mathrm{p} \leq 0,05$ utilizando o software Statistica 7.0. As respostas sensoriais foram avaliadas utilizando o software Assistat 7.7 (SILVA; AZEVEDO, 2016), aplicando o teste de Tukey $(\mathrm{p}<0,01)$.

\section{Resultados e Discussão}

O planejamento experimental $2^{2}$ completo, com 3 pontos centrais, foi usado para avaliar os efeitos das variáveis independentes nas respostas: $\mathrm{pH}$, acidez titulável, firmeza, consistência, coesividade e índice de viscosidade.

A concentração de goma xantana e sacarose na formação da bebida fermentada não influenciaram significativamente nos parâmetros de respostas: $\mathrm{pH}$, acidez titulável, firmeza e coesividade. Porém, foi observado uma tendência de aumento da firmeza com o aumento da concentração de goma xantana (Figura 1). Segundo Amatayakul et al. 
(2006), quanto maior a quantidade de sólidos totais, maior a firmeza do produto, isto é, maior o índice de consistência. $\mathrm{O}$ aumento da firmeza das amostras pode estar relacionado à produção de polissacarídeo vicioso (SABOKBAR; MOOSAVI-NASAB; KHODAIYAN, 2015; RANDAZZO et al., 2016).

Figura 1. Influência da concentração de goma xantana da firmeza das bebidas fermentadas.

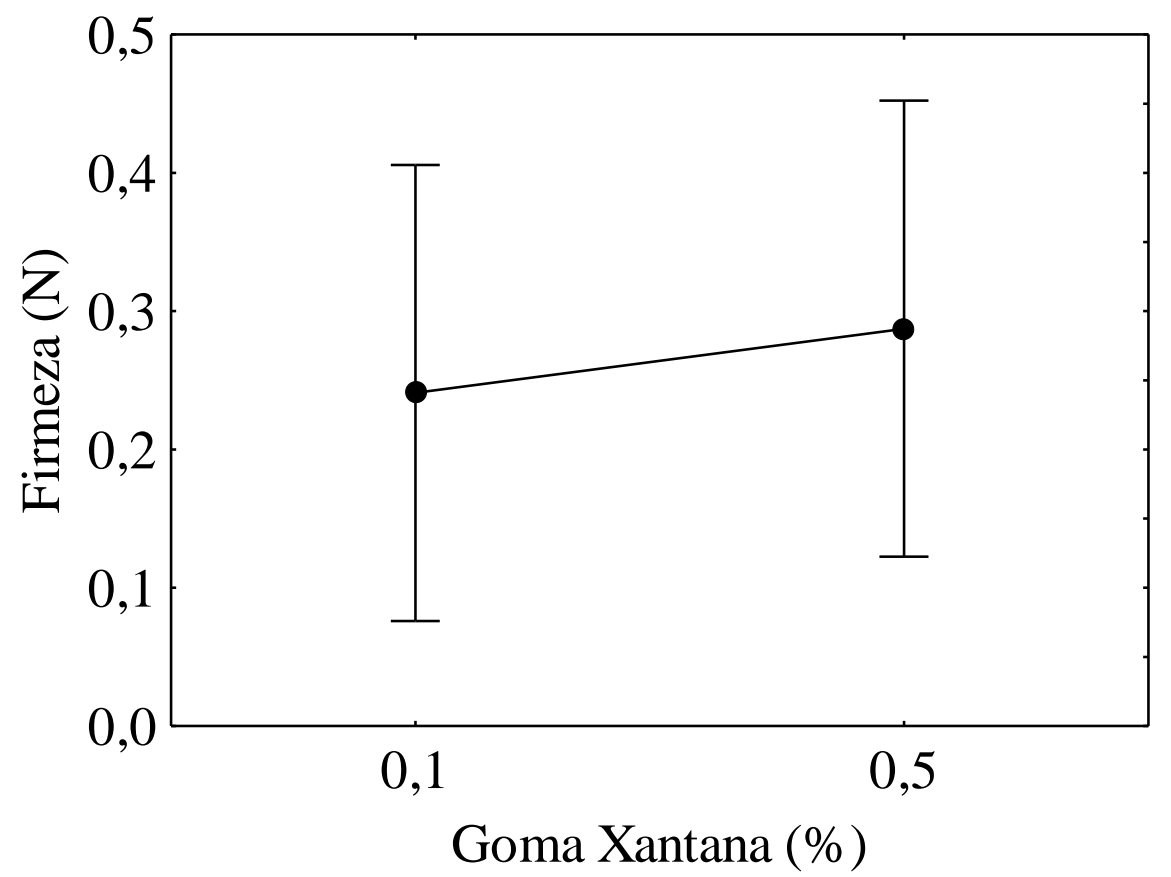

Fonte: Própria (2020).

Quanto a consistência e o índice de viscosidade, foi observado um efeito estatisticamente significativo para a variável concentração de goma xantana (Figura 2). O aumento da concentração de goma xantana resultou no aumento da consistência e do índice de viscosidade das bebidas obtidas, mostrando que em concentrações maiores a goma xantana é um aditivo útil para obtenção de uma bebida mais viscosa e mais consistente. Brandão et al. (2008) observou aumentou exponencialmente com o aumento da concentração de xantana na viscosidade de caldo de cana.

A viscosidade tem ligação direta com o teor de sólidos totais do produto, havendo aumento na viscosidade com o incremento da concentração de sólidos solúveis (GOMES; PENNA, 2009). 
Figura 2. Efeito das variáveis independentes nas respostas: a) consistência, b) índice de viscosidade.
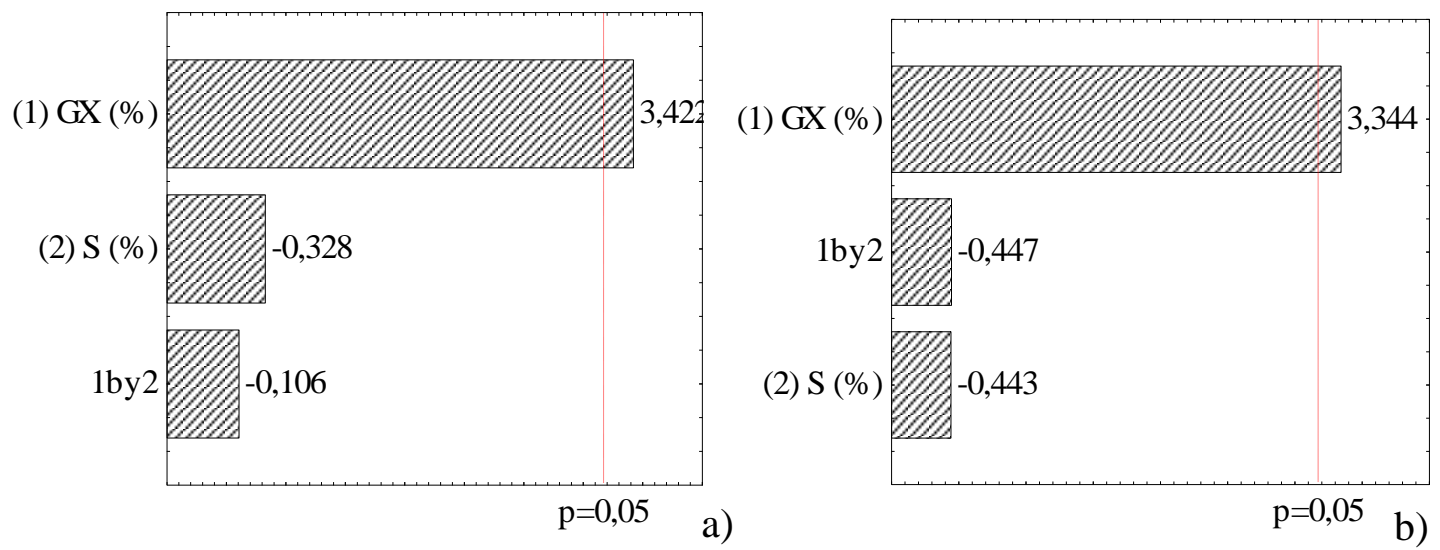

Fonte: Própria (2020).

Tabela 2. Analise de variância (ANOVA).

\begin{tabular}{llllll}
\hline Fonte de variação & SQ & GL & QM & F calculado & F tabelado \\
\hline Consistência & & & & & \\
Regressão & 9,7688 & 1 & 9,7688 & 18,77 & 10,01 \\
Resíduos & 2,6016 & 5 & 0,5203 & & \\
Falta de ajuste & 2,5373 & 3 & 0,8458 & 26,29 & 19,16 \\
Erro puro & 0,0644 & 2 & 0,0322 & & \\
Total & 12,3704 & 6 & & & \\
R & 0,7897 & & & & \\
Índice de viscosidade & & & & & \\
Regressão & 0,1062 & 1 & 0,1062 & 16,47 & \\
Resíduos & 0,0322 & 5 & 0,0064 & & 19,16 \\
Falta de ajuste & 0,0321 & 3 & 0,0107 & 137,01 & \\
Erro puro & 0,0002 & 2 & 0,0001 & & \\
Total & 0,1384 & 6 & & & \\
R & 0,7671 & & & & \\
\hline
\end{tabular}

Fonte: Própria (2020). 
A análise de regressão foi realizada para os parâmetros consistência e índice de viscosidade, obtendo os modelos lineares com coeficiente de determinação de 0,7897 e 0,7671, respectivamente. Os modelos obtidos, dados conforme as Equações (1) e (2), foram submetidos a análise de variância (ANOVA) (Tabela 2) e foi observado que o valor de $\mathrm{F}$ calculado foi maior que o valor de $\mathrm{F}$ tabelado, no entanto as razões entre os valores dos $\mathrm{F}$ foram inferiores a dois. Modelos com a razão dos valores de $\mathrm{F}$ superior a dois são considerados significativos e maiores que quatro são considerados preditivos.

$$
\begin{aligned}
& \text { Consistência }=1,357+7,814 \times \mathrm{GX} \\
& \text { Índice de viscosidade }=-0,102+0,815 \times \mathrm{GX}
\end{aligned}
$$

Em que: GX é a concentração de goma xantana (\%).

Apesar dos modelos obtidos terem apresentado coeficientes de determinação baixos e a razão dos valores de $\mathrm{F}$ inferior a dois, os efeitos da concentração da goma xantana na formulação das bebidas foi significativo para a consistência e para o índice de viscosidade. Os efeitos significativos foram utilizados para determinar os perfis dos valores previstos e a desejabilidade para os valores ótimos (Figura 3).

Figura 3. Perfil de valores previstos e desejabilidade em análise das variáveis dependentes: consistência e índice de viscosidade. Os valores destacados em negrito correspondem as concentrações ótimas de goma xantana e sacarose para obtenção de uma bebida fermentada com maior consistência e viscosidade.

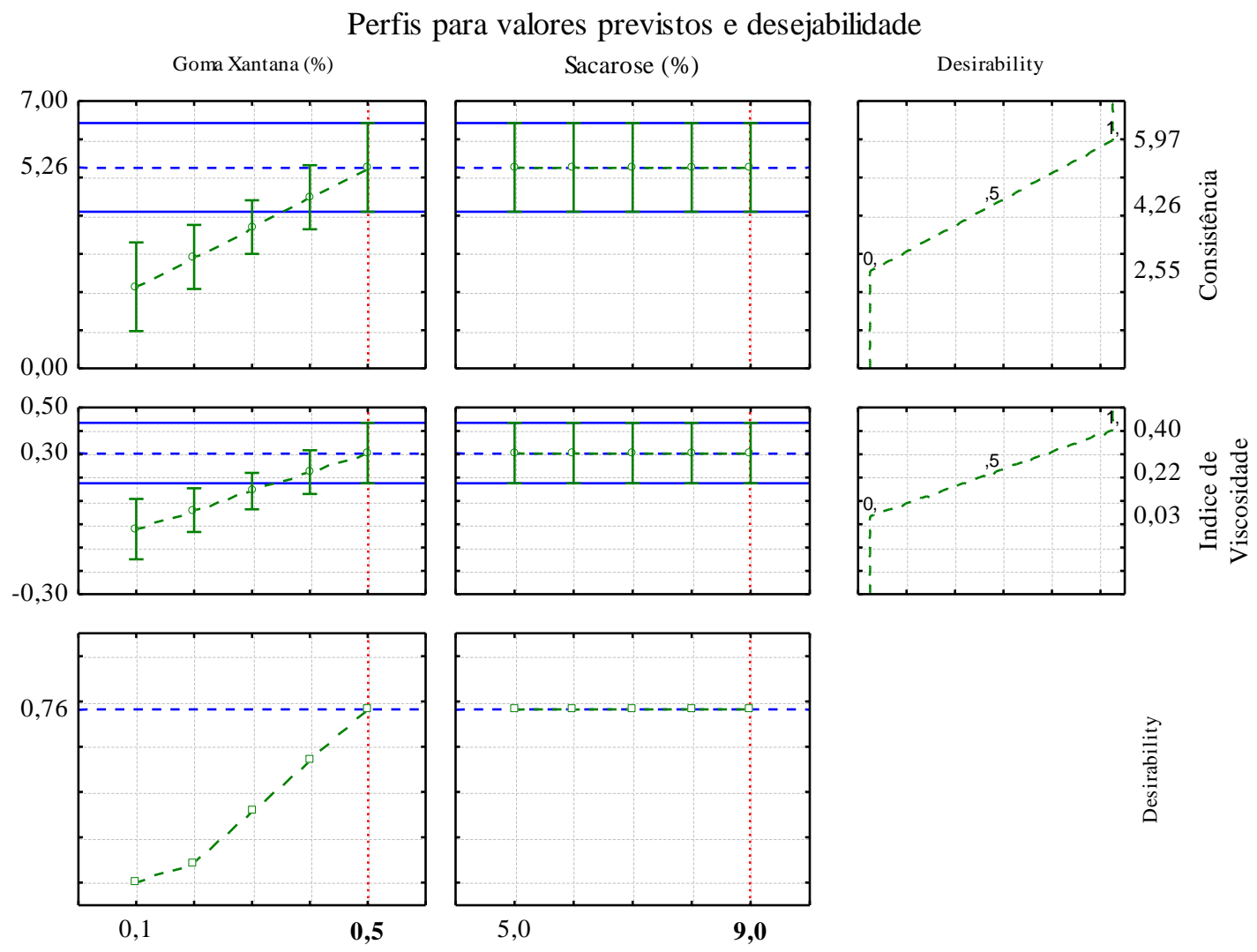


Fonte: Própria (2020).

Analisando a Figura 3, observa-se que os valores mais altos para os parâmetros de textura (consistência e índice de viscosidade) foram obtidos quando utilizado na formulação das bebidas $0,5 \%$ de goma xantana aliado a $9,0 \%$ de sacarose. A bebida formulada nessas condições desejáveis foi submetida a analise sensorial (experimento 4) junto as bebidas fermentadas obtidas nos experimentos $1(0,1 \%$ de goma xantana mais $5,0 \%$ de sacarose $)$ e 5 (0,3\% de goma xantana mais 7,0\% de sacarose) para análise da influência da consistência e índice de viscosidade no perfil sensorial das bebidas.

A análise sensorial é utilizada para evocar, medir, analisar e interpretar reações às características de alimentos e outros materiais da forma como são percebidos pelos sentidos da visão, olfato, gosto, tato e audição. Uma vez que a qualidade de um alimento implica, entre outras coisas, a satisfação do consumidor, é necessário que se tenha em mente que o próprio consumidor é quem deve ditar esta qualidade. Portanto cabe ao consumidor determinar os parâmetros de qualidade do produto. Neste ponto a análise sensorial se mostra extremamente importante (LUCIA; MININ; CARNEIRO, 2010)

Os escores sensoriais médios da avaliação organoléptica para as diferentes amostras de bebidas de iogurte são mostrados na Tabela 3. As pontuações sensoriais foram atribuídas utilizando uma escala hedônica de 9 pontos, onde o valor de 1 (desgostei muitíssimo) consiste em uma avaliação bastante antipática e o valor 9 (gostei muitíssimo) representa uma boa aceitação dos parâmetros sensoriais avaliados. Nas formulações da bebida fermentada analisadas sensorialmente, observou-se pontuações entre 5,06 (experimento 1, parâmetro doçura) a 7,10 (experimento 5, parâmetro aparência). Analisando a Tabela 3, em todos os parâmetros avaliados, observou-se que as bebidas fermentadas produzidas a base de extrato hidrossolúvel de aveia em infusão de maçã e canela teve uma aceitação média variando entre os escores equivalente a indiferente a gostei ligeiramente. É essencial que a bebida láctea tenha propriedades sensoriais adequadas para garantir que sejam aceitas pelos consumidores (MOLERO; BRIÑEZ, 2018).

Tabela 3. Médias de aceitação ${ }^{1}$ da bebida fermentada a base de extrato hidrossolúvel de aveia em infusão de maçã e canela resultante de três tratamentos com diferentes proporções de estabilizantes/espessante e sacarose.

\begin{tabular}{cccccc}
\hline \multirow{2}{*}{ Ensaios } & \multicolumn{5}{c}{ Parâmetros sensoriais } \\
\cline { 2 - 6 } & Aparência & Aroma & Sabor & Doçura & Textura \\
\hline 1 & $6,46 \pm 1,83 \mathrm{~b}$ & $6,48 \pm 1,64 \mathrm{a}$ & $5,22 \pm 1,83 \mathrm{~b}$ & $5,06 \pm 1,75 \mathrm{~b}$ & $5,48 \pm 1,95 \mathrm{~b}$
\end{tabular}




\begin{tabular}{cccccc}
\hline 4 & $6,96 \pm 1,52 \mathrm{ab}$ & $6,62 \pm 1,66 \mathrm{a}$ & $6,46 \pm 1,69 \mathrm{a}$ & $7,00 \pm 1,28 \mathrm{a}$ & $5,94 \pm 1,94 \mathrm{~b}$ \\
5 & $7,10 \pm 1,28 \mathrm{a}$ & $6,74 \pm 1,63 \mathrm{a}$ & $6,80 \pm 1,23 \mathrm{a}$ & $6,86 \pm 1,51 \mathrm{a}$ & $6,98 \pm 1,72^{\mathrm{a}}$ \\
\hline
\end{tabular}

Médias na mesma coluna e com letras iguais não diferem significativamente entre si pelo teste de Turkey $(\mathrm{p}<0,01), \mathrm{n}=50$ julgadores. ${ }^{1}$ Escala hedônica estruturada de nove pontos $(1=$ desgostei muitíssimo; $9=$ gostei muitíssimo). Os valores correspondem à com estimativa do desvio padrão.

Fonte: Própria (2020).

A análise estatística revelou que houve diferença estatística $(\mathrm{p}<0,01)$ entre as bebidas dos experimentos 1 e 5, para todos os parâmetros analisados, exceto o aroma, que não apresentou diferença estatística entre as diferentes formulações. As formulações dos experimentos 4 e 5 diferiram com significância estatística para o parâmetro textura, sendo observado uma pontuação mais alta neste parâmetro na bebida do experimento 5. Esses resultados indicam que a bebida com maior consistência e maior índice de viscosidade (experimento 4) obteve uma aceitação menor quanto a bebida obtida usando em sua formulação $0,3 \%$ de goma xantana e 7,0\% de sacarose (experimento 5).

Na Figura 4, são apresentados o perfil dos escores médios para cada formulação da bebida fermentada. Ao analisar a Figura 4, observa-se que a bebida obtida do experimento 5 apresentou a maior aceitação pelos julgadores, obtendo resultado bastante semelhantes para a bebida obtida no experimento 4, exceto para o parâmetro de textura das bebidas.

Figura 4. Perfil sensorial da bebida fermentada a base do extrato hidrossolúvel de aveia em infusão de maçã e canela resultante de três tratamentos com diferentes proporções de estabilizantes/espessante e sacarose.

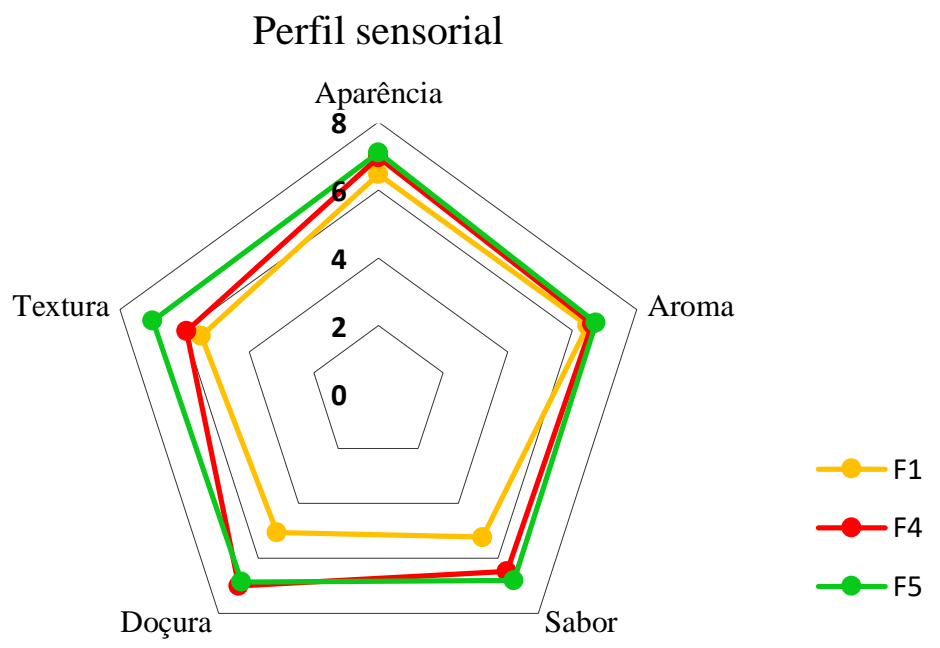

Fonte: Própria (2020). 
A aparência representa uma das primeiras características que irá refletir imediatamente ao julgamento e opinião do consumidor sobre um produto (KOMEROSKI, 2016). A avaliação sensorial indicou que o produto foi bem aceito pelos consumidores. Dessa forma, pode ser uma alternativa à inclusão de bebida fermentada a base do extrato hidrossolúvel de aveia em infusão de maçã e canela na alimentação, além de atender às necessidades de indivíduos com deficiência de lactase e vegetarianas.

Foi avaliado a intenção de compra das bebidas fermentadas a base de extrato hidrossolúvel de aveia em infusão de maça com canela obtidas nos experimentos 1, 4 e 5, e os resultados estão resumidos na Tabela 4. Observou-se que a bebida do experimento 1 obteve a menor pontuação, de acordo com a escala estruturada de intenção de compra, onde o valor de 5 é atribuída ao resultado positivo de que certamente compraria o produto, a o valor de 1, onde indica que certamente não compraria o produto avaliado. As bebidas dos experimentos 4 e 5 não apresentaram diferença estatística ( $p>0,01$ ), porém é observado uma tendência de preferência para a bebida obtida no experimento 5, utilizando 0,3\% de goma xantana e 7,0\% de sacarose em sua formulação.

Tabela 4. Médias de intenção de compra da bebida fermentada a base de extrato hidrossolúvel de aveia em infusão de maçã e canela resultante de três tratamentos com diferentes proporções de estabilizantes/espessante e sacarose.

\begin{tabular}{cc}
\hline Ensaios & Intenção de Compra \\
\hline 1 & $2,18 \pm 1,14 \mathrm{~b}$ \\
4 & $3,26 \pm 1,29 \mathrm{a}$ \\
5 & $3,74 \pm 1,04 \mathrm{a}$
\end{tabular}

Médias na mesma coluna e com letras iguais não diferem significativamente entre si pelo teste de Turkey $(\mathrm{p}<0,01), \mathrm{n}=50$ julgadores. Escala estruturada verbal de cinco pontos (5- Certamente compraria a 1 Certamente não compraria). Os valores correspondem à com estimativa do desvio padrão.

Fonte: Própria (2020).

Os resultados da análise sensorial revelam que as bebidas à base de extrato hidrossolúvel de aveia em infusão de maçã com canela apresentaram uma aceitação variando do neutra ao gostei ligeiramente. Silva et al. (2013) observaram os mesmos resultados para bebida láctea fermentada elaborada a partir do amido da amêndoa da manga Tommy Atkins mostrou-se viável para comercialização, por apresentar boas características sensoriais. Além disso, foi observado que a concentração do agente estabilizante/espessante (goma xantana) nas formulações das bebidas tem uma influência significativa na aceitação do produto. Já quanto a concentração de sacarose, o parâmetro 
doçura avaliado na análise sensorial revela que a concentração de 5\% não foi bem aceita, enquanto, as concentrações de 7 e $9 \%$ não diferiram na percepção sensorial dos julgadores.

De acordo com Mohr (2019), a demanda de mercado por alimentos que apresentem características sensoriais agradáveis ao público e que detenham componentes que tragam benefícios a saúde do consumidor, tem aumentado gradativamente nos últimos anos, por produtos que não contenham lactose e ingredientes de origem animal, está em expansão, tornando atraente a opção de alimento que contemple estas características.

\section{Conclusões}

A concentração da goma xantana tem um papel importante na textura das bebidas, onde foi observado que concentrações superiores a $0,3 \%$ não foi bem aceita pelos consumidores. A concentração de sacarose não apresentou efeito significativo na textura. No entanto, as concentrações de 7 e $9 \%$ receberam pontuações maiores, não diferindo entre si.

\section{Referências}

AMATAYAKUL, T.; SHERKAT, F.; SHAH, N. P. Physical characteristics of set yoghurt made with altered casein to whey protein ratios and EPS-producing starter cultures at 9 and 14\% total solids. Food hydrocolloid, v. 20, n. 2-3, p. 314-324, 2006.

ANGELOV, A.; YANEVA-MARINOVA, T.; GOTCHEVA, V. Oats as a matrix of choice for developing fermented functional beverages. Journal of Food Science and Technology, v. 55, n. 7, p. 2351-2360, 2018. https://doi.org/10.1007/s13197-018-3186$\mathrm{y}$

CODA, R.; LANERA, A.; TRANI, A.; GOBBETTI, M.; CAGNO, R. Yogurt-like beverages made of a mixture of cereals, soy and grape must: Microbiology, texture, nutritional and sensory properties. International Journal of Food Microbiology, v. 155, n. 3, p. 120-127, 2012. https://doi.org/10.1016/j.ijfoodmicro.2012.01.016

BELTRAN, L. B. Desenvolvimento e caracterização de sorvete vegano de chocolate. Orientador: Maria Josiane Sereia. 2018, f. 51. Trabalho de conclusão de curso (Graduação em Tecnologia em Alimentos). Universidade Tecnológica Federal do Paraná. Campo de Mourão-PR, 2018.

BRANDÃO, L. V.; NERY, T. B. R.; MACHADO, B. A. S.; ESPERIDIÃO, M. C. A.; DRUZIAN, J. I. Production of xanthan gum obtained from sugarcane. Food Science 
and Technology, v. 28, p. 217-222, 2008.

DEZIDERIO, M. A. Desenvolvimento de bebida fermentada funcional de origem vegetal. Orientador: Rodrigo Rodrigues Petrus. 2019, f. 91. Universidade de São Paulo Faculdade de Zootecnia e Engenharia de Alimentos. Dissertação (Mestrado em Engenharia de Alimentos), Pirasssununga-SP, 2019.

GOBBETTI, M.; CAGNO, R.; ANGELIS, M.; CAGNO, R. DI; ANGELIS, M. Functional microorganisms for functional food quality. Food Science and Nutrition, v. 50, n. 8, p. 716-727, 2010. https://doi.org/10.1080/10408398.2010.499770

KOMEROSKI, M. R. A relevância dos componentes sensoriais nas escolhas alimentares. Orientadora: Viviani Ruffo de Oliveira. 2016, f. 41. Trabalho de conclusão de curso (Graduação em Nutrição). Universidade Federal do Rio Grande do Sul, Porto Alegre, 2016.

KREISZ, S.; ARENDT, E. K.; HÜBNER, F.; ZARNKOV, M. Cereal-based gluten-free functional drinks. Gluten-Free Cereal Products and Beverages, p. 373-392, 2008. https://doi.org/10.1016/B978-012373739-7.50018-6

KIZZIE-HAYFORD, N; JAROS, D; ZAHN, S; ROHM, H. Effects of protein enrichment on the microbiological, physicochemical and sensory properties of fermented tiger nut milk. Food Science and Technology, v. 74, p. 319-324, 2016.

LUCIA, S. M. D.; MININ, V. P. R.; CARNEIRO, J. D. S. Análise sensorial de alimentos. In: MINIM, V. P. R. 2 ed. Viçosa: Editora UFV, p. 13-15, 2010.

MATTILA-SANDHOLM, T. VTT on lactic acid bacteria. Valtion Teknillinen Tutkimuskeskus Symposium, v. 156, p. 1-10, 1998.

MOLERO, M. S.; BRIÑEZ, W. J. Probiotics Consumption Increment through the Use of Whey-Based Fermented Beverages. Chemistry, p. 115-132, 2018.

http://dx.doi.org/10.5772/intechopen.72362

MOHR, F. B. M. Fermentados tipo iogurte sabor pitanga: alimento funcional e aceitação sensorial. Orientador: Américo Wagner Júnior. 2019, f. 109. Tese (Doutorado em Agronomia), Universidade Tecnológica Federal do Paraná, Pato Branco-PR, 2019.

MUHAMMAD, D. R. A.; DEWETTINCK, K. Cinnamon and its derivatives as potential ingredient in functional food - A review. International Journal of Food Properties, v. 20, p. 1-27, 2017. https://doi.org/10.1080/10942912.2017.1369102

PRADO, F. C.; PARADA, J. L.; PANDEY, A.; SOCCOL, C. R. Trends in non-dairy probiotic beverages. Food Research International, v. 41, n. 2, p. 111-123, 2008. https://doi.org/10.1016/j.foodres.2007.10.010

RANDAZZO, W.; CORONA, O.; GUARCELLO, R.; FRANCESCA, N.; GERMANÀ, M. A.; ERTEN, H.; MOSCHETTI, G.; SETTANNI, L. Desenvolvimento de novas bebidas não lácteas de sucos de frutas do Mediterrâneo fermentadas com micro- 
organismos de kefir de água. Microbiol de alimentos, v. 54, p. 40-51, 2016. https://doi: 10.1016/j.fm.2015.10.018.

SABOKBAR, N.; MOOSAVI-NASAB, M.; KHODAIYAN, F. Preparação e caracterização de uma nova bebida à base de suco de maçã e soro de leite fermentada usando grãos de kefir. Food Science and Biotechnol, v. 24, p. 2095-2104, 2015. https://doi: 10.1007/s10068-015-0278-6.

SALMERÓN, I.; THOMAS, K.; PANDIELLA, S. S. Effect of potentially probiotic lactic acid bacteria on the physicochemical composition and acceptance of fermented cereal beverages. Journal of Functional Foods, v. 15, p. 106-115, 2015.

https://doi.org/10.1016/j.jff.2015.03.012

SILVA, G. A. S.; CAVALCANTI, M. T.; ALMEIDA, M. C. B. M.; ARAÚJO, A. S.; CHINELATE, G. C. B.; FLORENTINO, E. R. Utilização do amido da amêndoa da manga Tommy Atkins como espessante em bebida láctea. Revista Brasileira de Engenharia Agrícola e Ambiental, v. 17, n. 12, p. 1326-1332, 2013.

SILVA, F. A. S.; AZEVEDO, C. A. V. The Assistat Software Version 7.7 and its use in the analysis of experimental data. African Journal of Agricultural Research, v. 11, n. 39, p. 3733-3740, 2016. https://doi.org/10.5897/AJAR2016.11522

SHAH, A.; MASOODI, F. A.; GANI, A.; ASHWAR, B. A. Newly released oat varieties of himalayan region -Techno-functional, rheological, and nutraceutical properties of flour. Food Science and Technology, v. 70, p. 111-118, 2016. https://doi.org/10.1016/j.lwt.2016.02.033

SHORI, A. B. Influence of food matrix on the viability of probiotic bacteria: A review based on dairy and non-dairy beverages. Food Bioscience, v. 13, p. 1-8, 2016.

YÉPEZ, A; RUSSO, P; SPANO, G; KHOMENKO, I, BIASIOLI, F; CAPOZZI, V, AZNAR, R. In situ riboflavin fortification of different kefir-like cereal-based beverages using selected Andean LAB strains. Food Microbiology, v. 77, p. 61-68, 2019.

WEBER, F. H.; GUTKOSKI, L. C.; ELIAS, M. C. Caracterização química de cariopses de aveia (Avena sativa L.) da cultivar UPF 18. Ciência e Tecnologia de Alimentos, v. 22, n. 1, p. 39-44, 2002. https://doi.org/10.1590/s0101-20612002000100007 